\title{
The effect of one positive reinforcement on helping with cost
}

\author{
L. P. McGOVERN and JAN L. DITZIAN \\ State University of New York, College at Buffalo, Buffalo, New York 14222 \\ and \\ STUART P. TAYLOR \\ Kent State University, Kent, Ohio 44242
}

\begin{abstract}
Twenty male college student subjects were divided into two groups. One group received reinforcement when they helped a female confederate following a request for aid, the other group did not. The helping gesture involved the volunteering by the subject to take an electrical shock which he believed could go to the confederate. The reinforcement was a "Thank you" from the confederate. Subjects who received the reinforcement continued to volunteer for shock while those who did not disctontinued volunteering.
\end{abstract}

The relatively high rates of helping behavior observed by Berkowitz and his co-workers (e.g. Berkowitz \& Conner, 1966; Berkowitz \& Daniels, 1963) led these experimenters to posit the workings of a social responsibility norm. Other authors have suggested more basic motivations for altruistic behavior. Campbell (1965), for example, has stated that humans possess an innate altruistic drive. Further, Weiss, Boyer, Lombardo and Stich (1973 note that: "new data from our laboratory indicate that the roots of altruistic behavior are so deep that people not only help others, but find it rewarding to do so."

It is difficult to reconcile these points of view with the results of the research reported by Latane and Darley (1970). Indeed, considering that the mere presence of others often served to reduce helping rates to extremely low levels (e.g. Latané \& Rodin, 1969), it would seem that the suggested motivations are often of slight effect.

There seems to be one major difference between studies which show high and those which reveal low rates of helping. In the former studies, there is usually little or no cost to the helper; in the latter, subjects often risk social disapproval or physical pain. In the Weiss et al (1973) study, for example, helping was without penalty. Subjects showed a decrease in response latency when the effect of a short latency was the early release of a co-worker from electric shock. Helping in the real world most often entails some cost to the helper. Thus, if someone has fallen through the ice, the potential benefactor risks getting cold and wet. The question then, in relation to extralaboratory helping behavior, is not simply one of whether altruistic behavior can be modified, but whether it can be

This paper is sponsored by F. Robert Treichler who takes full editorial responsibility for it. modified or even maintained in the face of negative consequences to the helper.

There may be an innate need to help. Considering the malleability of human behavior, the need may not be evidenced because of lack of reinforcement. It is possible that the low levels of helping often observed in situations in which there is cost to the helper could stem from the inadequate reinforcement of previous prosocial behavior. The present study was conducted to test the proposition that a positive reinforcement could maintain or enhance helping, even when there was cost to the helper, while its absence would lead to a decline in helping.

\section{METHOD}

\section{Subjects and Design}

The subjects were 20 male undergraduates enrolled in an introductory psychology course at Kent State University. Subjects were divided into two groups of 10 subjects each. Members of one group received a "thank you" when they volunteered for shock on the request trial; members of the other group did not.

\section{Procedure}

Subjects were paired with a female confederate because previous research had shown that subjects emitted levels of helping with a male confederate which were too low to modify. Shock electrodes and dummy physiological recording electrodes were strapped to the arms of the subject and confederate who were seated side by side at matching one arm desks. Following the determination of their shock thresholds, a tape recording of the test instructions was played. The instructions stressed physiological measurement. These included the statements:

"We are interested in whether or not accepting an electric shock or watching another person take an electric shock leads to physiological arousal."

"There are two conditions in this experiment, the both condition and the one condition. ON the box in front of you are two colored lights and a red button. One light is labeled the both light; the other is labeled the one light. When the both light 
lights up, it means that both subjects are scheduled to receive an electric shock. When the one light lights up, shock is delivered to the subject who presses the red button within 10 seconds. If no one presses the red button within this period, the shock will go to only one subject. The subject that will recive the shock is determined in a random manner."

For a "both" trial, the appropriate signal light came on for $10 \mathrm{sec}$. At the end of this period, shock was delivered to the real subject and a signal to feign shock recption through arm jerk was given to the confederate. For a "one" trial, the appropriate light came on and stayed on for $10 \mathrm{sec}$ unless the subject pressed the button. The confederate never pressed. Shocks or a signal to feign shock reception were given in a predetermined order when the subject did not respond. Trials were run with a 15 -sec ITI. There were three "both" trials and 18 "one" trials. The order consisted of three repetitions of the cycle of a "both" trial followed by six "one" trials. When the second "both" light flashed, and a shock was presumably received, the confederate exclaimed loudly in pain ("Ow!") at the shock. At the onset of the "one" light for the next trial she requested of the subject: "Would you take it?" If the subject took the shock in the reinforcement condition, she said, "Thank you" If he did not, she said nothing. She also said nothing if the shock was taken in the no reinforcement condition. There was no further comment and no repetition of "thank you." The participants were enjoined from commmunicating while in the experiment. Ostensibly, this was because of the physiological recording; in fact, it was to control their interaction. No subject expressed suspicion of the deception during debriefing.

\section{RESULTS AND DISCUSSION}

Only a small proportion of subjects chose to receive the shock prior to the request for aid. Analysis of variance of the prerequest frequency data indicated that the reinforcement and no-reinforcement groups did not differ significantly in helping during the prerequest block of trials $(\mathrm{F}=.599, \mathrm{df}=1 / 18)$.

There was a dramatic increase in helping on the trial following the confederate's appeal. Whereas only $20 \%$ of subjects volunteered for the shock on the trial prior to the request, $75 \%$ of subjects accepted the shock on the request trial. These results would appear to indicate that a direct personal appeal by a distressed victim can appreciably influence helping behavior, even when the consequences of helping are painful. A specific request was not sufficient to sustain helping, however. While the percentage of subjects who helped the confederate in the reinforcement group remained high, the percentage who helped in the no-reinforcement group dropped immediately. Their response rate returned to prerequest levels on the next trial and in the following trials never exceeded prerequest levels.

An analysis of variance was performed for the proportions of helping before and after the seventh "one" trial, the request trial. The data was treated as a 2 (conditions) by 2 (pre- and postrequest blocks) factorial design. The dependent measure was number of times the subject volunteered for shock on "one" trials. This analysis showed a significant effect for the reinforcement condition $(\mathrm{F}=27.45 ; \mathrm{df}=1 / 18$; $\mathrm{p}<.001)$, a significant effect for blocks $(\mathrm{F}=24.10 ; \mathrm{df}=$ $1 / 18 ; \mathrm{p}<.001)$ and a significant interaction $(\mathrm{F}=11.98$; $\mathrm{df}=1 / 18 ; \mathrm{p}<.005)$. Posttest analysis (Newman-Keuls) confirmed that the two groups did not differ significantly for the prerequest trials $(p>.25)$. On the other hand, it also showed that the reinforced group differed significantly $(p<.001)$ from the nonreinforced group for the postrequest trials. The Fisher exact test showed no significant difference between the two groups on the request trial.

It is interesting that after only one positive reinforcement, response rates for the reinforcement group continued at a high level throughout the balance of the experiment. This was the case even though each helping gesture also produced electric shock. In fact, the frequency of helping was higher for the reinforcement group in the final block of trials then it was in the second block. Such a strong effect for a single reinforcement, coupled with the high helping rates for all subjects on the request trial, suggests an approach-avoidance conflict in the helping situation. There is apparently some motivation to help. If the helping behavior is not reinforced, however, the effect of negative consequences is immediately reasserted.

Even though their helping rates differed, both the no-reinforcement and reinforcement groups perceived the confederate as receiving a more severe shock than they themselves received. Both groups rated the confederate's shock as significantly more unpleasant. Subjects also rated the confederate and rated themselves, as they believed the confederate would rate them, on six-point scales for 29 adjective pairs. Both the ratings of the confederate and the ratings of the subjects of themselves seem dominated by the postexperimental needs of nonreinforced and thus, nonhelping subjects. These subjects showed a negative reaction to the confederate. They rated her as significantly more unfair, unpredictable, cowardly, ugly, bad, and ill-humored than the reinforced subjects did. They rated themselves as more unsympathetic, bloodthirsty, unfair, destructive, unreasonable, ill-humored, rejective, and revengeful.

These findings have implications for both the laboratory study and the social control of altruistic behavior. The present results demonstrate the importance of positive consequences when there is cost to the helper. Although there may be a need to help and particular events may elicit a helping gesture, the chances that the gesture will recur seem definitely reduced if it is not acknowledged or rewarded. If the present results are an indication, a nonreinforced helper will walk away from the experience somewhat resentful and less likely to help on the next occassion. It would seem therefore, that there is a need for American society to become more positively responsive to the good samaritan. Presently the media and other societal institutions all but ignore such individuals. 


\section{REFERENCES}

Berkowitz, L., \& Conner, W. H. Success failure and social responsibility. Journal of Personality and Social Psychology, $1966,4,664-669$.

Berkowitz, L., \& Daniels, L. Responsibility and dependency. Journal of Abnormal and Social Psychology, 1963, 66, $429-436$.

Campbell, D. T. Ethnocentric and other altruistic motives. Nebraska Symposium on Motivation, 1965, 13, 282-311.
Latane, B., \& Darley, J. M. The unresponsive bystander: Why doesn't he help? New York: Appleton-Century-Crofts, 1970 Latane, B., \& Rodin, J. A lady in distress: Inhibiting effects of friends and strangers on bystander intervention. Journal of Experimental Social Psy chology, 1969, 5, 189-209.

Weiss, R. F., Boyer, J. L., Lombardo, J. P., \& Stitch, M. H. Altruistic" drive and altruistic reinforcement. Journal of Personality and Social Psychology, 1973, 25, 390-400.

(Received for publication January 13, 1975.) 